\title{
Analysis of a novel system to provide fresh water
}

\author{
D. F. Dyer \\ Department of Mechanical Engineering, Auburn University, USA
}

\begin{abstract}
In thermodynamics one learns that there are four factors that lead to the degradation of energy. One of these factors is mixing. A classic example of mixing occurs when fresh water mixes with salt water in the ocean. The total attention of the world towards producing fresh water from ocean water is the use of desalination (usually reverse osmosis). This paper clearly demonstrates that this approach ignores a potentially much better solution by capturing fresh water before it mixes with ocean water. An example is taken showing the potential to provide the total agricultural needs for the state of California by using a small fraction of the Columbia River discharge into the Pacific Ocean and conveying it approximately $1130 \mathrm{~km}$ by an aqueduct to the Sacramento River that serves the agricultural district of California. The design of the aqueduct is done using the Manning formula for open channel flow. An optimization analysis is performed based on this formula to assess the optimum configuration and slope of the aqueduct, the cost of that aqueduct, the power consumed in transporting the water, and the total cost of the water delivered. These results are compared to the energy and monetary costs for providing water by desalination. It is shown that desalinated water costs more than ten times water delivered by the proposed method. The greenhouse emissions from the proposed method are only a fraction of that due to desalination. Finally, the cost of water delivered by the proposed method is less than $25 \%$ of current average US cost for water.

Keywords: open channel flow, water supply, greenhouse gas.
\end{abstract}

\section{Introduction}

Worldwide there is an increasing scarcity of water. Conservation and improved equipment to minimize use of water can help alleviate the problem. However, the 
population is expected to increase by $50 \%$ in the next 40 years [1]. This worldwide population increase along with a desire to improve the standard of living will greatly exacerbate the already dire water situation. The world's reaction to this problem has been to install reverse osmosis desalination plants (SWRO). Just in the next 5 years, the capacity of installed SWRO is expected to double [2]. This paper is a serious challenge to this approach suggesting that there is a better way. In this paper it is proposed to collect some of the outflow of fresh water from the mouth of a river, as it is about to mix with ocean water and then transport this water to a usable point. For brevity this system is called "RWT" for River Water Transport. As an example of the potential for RWT, there is more water leaving the Mississippi river than the entire United State uses [3].

A very important principle from thermodynamics strongly suggests that the current approach to alleviating water scarcity (SWRO) is wrong. One of the four factors from thermodynamics that cause energy to degrade (universal entropy to increase) is mixing. A good example of these phenomena is the mixing of fresh water from rivers into salt water in the ocean. What is happening now is fresh water from rivers is mixed with ocean water and then the mixing process is reversed by use of SWRO. SWRO involves a tremendous degradation of energy in that high quality electrical energy is converted into water with almost no energy in it. Desalination then is inherently bad because it uses enormous amounts of high-quality energy that is also one of the earth's dwindling resources. In addition, it contributes greatly to global warming because of the power plants required to generate electricity. Obviously there is no need for desalination if one captures the river water before it is mixed. This process will require careful attention to the method used to draw water from the mouth of a river and it will require a method to transport the water to its desired delivery point.

Environmentalists will undoubtedly attack a system that draws water from the mouth of a river that is discharging into the ocean. There should be no concern about the effect of the RWT system upstream of the river's mouth because no water is being drawn except at the point where the river flows into the ocean. Certainly, there are major environmental concerns including danger to the ecological system between the river mouth and ocean, possible salt intrusion with damage to the ecological upstream system, fish migration, etc. Fortunately, there is a system that could potentially alleviate some of these problems. This system consists of the use of a weir. It is beyond the scope of this paper to detail the proper design of the system, but thousands of these systems are in place and can allow the RWT system to work without significant environmental damage [4].

Fortunately, we have a great heritage from the Romans who over 2000 years ago built more than $800 \mathrm{~km}$ of aqueduct systems to supply water. The aqueducts used to supply Rome furnished more than a million cubic meters of water daily. A typical Roman aqueduct was mostly a shallow, lined trench with rock structures bridging across valleys. The Romans used a typical slope of $0.0002 \mathrm{~m} / \mathrm{m}$.

In this paper, a description and analysis of the RWT system is given. An example is considered in which water from the Columbia River is transported to central California to supply all of the agricultural needs of the State for water. An optimization using the fundamental fluid equations is used to provide 
an approximate idea of the size, infrastructure cost, and operating costs of the system. These data are then compared to the equivalent performance of SWRO.

\section{Description of RWT system}

California agricultural use of water is approximately $1000 \mathrm{~m}^{3} / \mathrm{s}$ [5]. The average discharge rate of water from the Columbia River into the ocean is $7500 \mathrm{~m}^{3} / \mathrm{s}$ according to Kemmerer [6]. Hence, diverting about 13.3\% of the Columbia River would satisfy California's agricultural need. The proposed RWT system consists of an aqueduct that transfers $1000 \mathrm{~m}^{3} / \mathrm{s}$ of water from the mouth of the Columbia River at Astoria, Oregon to the Sacramento River near Sacramento, California. The distance required is approximately 1130 kilometres. The elevation change between these two points is essentially zero. In this paper it is assumed that the aqueduct slopes downward from Oregon to California at a small rate. It is not the object of this paper to provide a detailed design of the aqueduct system. However, to provide a rough cost estimate the following ideas are given. First the system would use the natural topography of the western coastal region. The aqueduct will use pumping stations to pump water up hills from approximately sea level. The pumps are powered by electrical motors. The aqueduct would then gently slope downward in the side of the hill until it reached approximately sea level. The process would then be repeated. Defining the number of pumping stations would require a detailed layout of the system. Hence, the aqueduct would be primarily in ground requiring almost no structural support. For estimating the amount of material needed to construct the aqueduct it is assumed that concrete 10 $\mathrm{cm}$ thick is used since it is not a load bearing structure. It is even possible to construct the aqueduct from much cheaper materials such as geo textiles. The aqueduct itself is assumed to be rectangular in cross section and open to atmosphere.

It is interesting to note that evaporation of water from the aqueduct has no material effect on the system. The average evaporation rate in the Western United States is less than $10 \mathrm{~mm} /$ month [7]. For a canal that is $1160 \mathrm{~km}$ long and $100 \mathrm{~m}$ wide the evaporation rate would be $1,160,000$ cubic meters/month. Dividing this amount of evaporation by the number of seconds in a month, gives a rate of evaporation equal to $0.45 \mathrm{cubic} / \mathrm{meters} / \mathrm{second}$. This amount of evaporation is inconsequential compared to the flow of 1000 cubic meters/second and is subsequently ignored in this paper.

\section{Analysis of RWT system}

The analysis required is to determine the geometrical cross section of an aqueduct that will carry a given flow of water with a given slope and to determine the cost and power requirements for the aqueduct. The fluid flow equation that describes this situation is the Gauckler-Manning formula (Gauckler [8] and Manning [9]). The Gauckler-Manning formula states:

$$
\mathrm{Q}=(1 / \mathrm{n})\left(\mathrm{R}^{.667}\right)\left(\mathrm{S}^{.5}\right)(\mathrm{A})
$$

where $Q$ is the flow rate in $\mathrm{m}^{3} / \mathrm{s}$; 
$\mathrm{n}$ is the Gauckler-Manning coefficient that depends on surface roughness. A value of 0.016 is used which describes a surface slightly more rough than concrete; $\mathrm{R}=(\mathrm{d})(\mathrm{w}) /(2(\mathrm{~d})+\mathrm{w})$ is the hydraulic radius which is the aqueduct cross sectional area divided by the wetted perimeter measured in meters;

$\mathrm{S}$ is the slope of the channel bed, $\mathrm{m} / \mathrm{m}$;

$\mathrm{d}$ is water depth, $\mathrm{m}$;

$\mathrm{w}$ is width of aqueduct, $\mathrm{m}$;

$A=(d)(w)$ is the cross sectional area of water flow in $\mathrm{m}^{2}$.

Eq (1) is solved by a trial and error procedure as follows:

The value of $\mathrm{Q}$ is known. $\mathrm{Q}=1000 \mathrm{~m}^{3} / \mathrm{s}$;

A value of the water depth (d), and slope (S) is specified;

A value for the aqueduct width, $\mathrm{w}$, is guessed;

A value of $R$ is calculated.

The values of $\mathrm{R}, \mathrm{n}, \mathrm{w}$, and $\mathrm{S}$ are substituted into the right hand side of Eq (1). If the right hand side of Eq (1) equals $\mathrm{Q}$, the guessed value of $\mathrm{w}$ is correct. The calculation procedure described above is used to determine the aqueduct geometry for a number of slopes ranging from $0.00002 \mathrm{~m} / \mathrm{m}$ to $0.0003 \mathrm{~m} / \mathrm{m}$ and for depths of $6.1 \mathrm{~m}$ and $9.2 \mathrm{~m}$.

These calculations are made to determine the optimum geometry and slope for the aqueduct. For each case considered, the following parameters are determined using the formulation and values shown.

\subsection{Cost to construct the aqueduct}

The volume of concrete required multiplied by the cost of concrete per volume yields the total material cost to construct the aqueduct. Based on comparison with other construction projects, it is assumed that the total project cost is thirty times the concrete material cost. Therefore, the total cost to construct the aqueduct is

$$
\mathrm{TC}=30(2 \mathrm{~d}+\mathrm{w})(\mathrm{t})(\mathrm{C})(\mathrm{L})
$$

$\mathrm{TC}=$ total cost of aqueduct system in dollars;

$\mathrm{t}=$ thickness of concrete $0.101 \mathrm{~m}$;

$\mathrm{C}=$ cost of concrete per unit volume $=\$ 117 / \mathrm{m}^{3}$;

$\mathrm{L}=$ length of aqueduct in $\mathrm{m}=1,130,000 \mathrm{~m}$.

It is shown subsequently in this paper that the minimum cost to construct the proposed RWT system using the above values is approximately twenty billion dollars. This is approximately $\$ 28,500,000 /$ mile. According to [10] the cost to "construct a new 6-lane Interstate highway - about $\$ 7$ million per mile in rural areas." Since road construction is similar to the proposed aqueduct, a factor of 4 is a conservative estimate of the cost one would expect for the proposed RWT system.

\subsection{The power required to provide the necessary pumping to overcome the elevation change in the aqueduct to accommodate its given slope}

The total increase in elevation is the length of canal times its slope. The pressure due to this change in elevation is the product of the water density and elevation 
change. The power consumed by the pump is the product of the volume flow of water and pressure head due to the elevation change divided by pump efficiency. Hence, the power consumed by the pump

$$
\mathrm{P}=(\mathrm{S})(\mathrm{L})(\gamma)(\mathrm{Q}) /[(\eta)(106)
$$

$\mathrm{P}$ is the required pumping power in $\mathrm{MW}$;

$\gamma=$ density of water $=9810 \mathrm{~N} / \mathrm{m}^{3}$;

$\eta=$ efficiency of pump assumed to be 0.9 .

\subsection{Cost of energy plus payment of capital expenditure per $1000 \mathrm{~m}^{3}$ of water}

The cost of energy is the time that it takes to make $1000 \mathrm{~m}^{3}$ of water multiplied by the pump power and the unit cost of power. Since this example is based on making $1000 \mathrm{~m}^{3} / \mathrm{s}$ of water, the time to produce this amount of water is one second or $1 / 3600 \mathrm{hr}$. Hence,

$$
\mathrm{PC}=(\mathrm{P})(\mathrm{MC})(\tau)
$$

$\mathrm{PC}=\$$ Power cost $/ 1000 \mathrm{~m}^{3}$ of water;

$\mathrm{P}$ is in $\mathrm{MW}$;

$\mathrm{MC}$ is the cost of power in $\$ / \mathrm{MW}-\mathrm{hr}=100 \$ / \mathrm{Mw}-\mathrm{hr}$; $\tau$ is time to flow $1000 \mathrm{~m}^{3} / \mathrm{s} \mathrm{in} \mathrm{hr}=1 / 3,600 \mathrm{hr}$.

The cost of capital per $1000 \mathrm{~m}^{3}$ of water to fund the construction of the project is the product of the total cost of the RWT system, the ratio of time to produce $1000 \mathrm{~m}^{3}$ to time in one year and the rate of return expected by the investors. Hence,

$$
\mathrm{CC}=(\mathrm{TC})(\mathrm{f})(\mathrm{RR})
$$

$\mathrm{CC}$ is capital cost per $1000 \mathrm{~m}^{3}$ of water;

TC is total capital cost of system;

$\mathrm{f}=$ fraction of annual time required to make $1000 \mathrm{~m}^{3} / \mathrm{s}$, i.e.;

$\mathrm{f}=(1 / 3600) \mathrm{hr} /(8760 \mathrm{hr} / \mathrm{yr})$;

$\mathrm{RR}$ is the annual rate of return.

Therefore, the total cost of energy and capital per $1000 \mathrm{~m}^{3}$ of water flow, TCEC, is

$$
\mathrm{TCEC}=\mathrm{PC}+\mathrm{CC}
$$

\subsection{The Froude Number to determine if the flow is stable}

The Froude number, Fr, is a dimensionless ratio of inertia to gravitational force on a fluid element. It is used to determine the state of flow in an open channel. If the Froude number is less than unity the flow will be stable (placid and calm) since its inertia forces are less than its weight. The Froude number is calculated from its definition. For a rectangular channel

$$
\operatorname{Fr}=[Q /(d)(w)] /[(g)(d)]^{0.5}
$$




\section{Analysis of RWT system}

The trial and error procedure to solve the Gauckler-Manning equation (see section 3 ) for the width of the aqueduct as a function of its height and slope gives the solution shown in Table 1.

Table 1: Aqueduct dimensions as a function of slope.

\begin{tabular}{|c|c|c|}
\hline Aqueduct height, $\mathbf{m}$ & Aqueduct slope, $\mathbf{m} / \mathbf{m}$ & Aqueduct width, $\mathbf{m}$ \\
\hline 6.1 & 0.00005 & 102.1 \\
\hline 6.1 & 0.00015 & 62.9 \\
\hline 6.1 & 0.00025 & 50.8 \\
\hline 9.2 & 0.00005 & 54 \\
\hline 9.2 & 0.00015 & 35.2 \\
\hline 9.2 & 0.00025 & 29.3 \\
\hline
\end{tabular}

The following results are calculated based on the calculation procedures described in section 3.1, 3.2, 3.3, and 3.4. In addition, comparative data for reverse osmosis desalination are given.

First, the cost to construct the aqueduct system as a function of its slope is given in Figure 1. As the figure shows, the construction cost goes up exponentially as the slope decreases. This is due to the fact that as the slope decreases, the cross sectional area must increase to overcome the reduction in potential energy of the water per unit length. The increase in cross sectional area increases the size of the system and the volume of concrete and excavation required. Figure 1 also shows that the cost increases as the depth decreases. Finally, Figure 1 shows that the really significant increase in cost occurs below a slope of approximately $0.01 \mathrm{~m} / 100 \mathrm{~m}$.

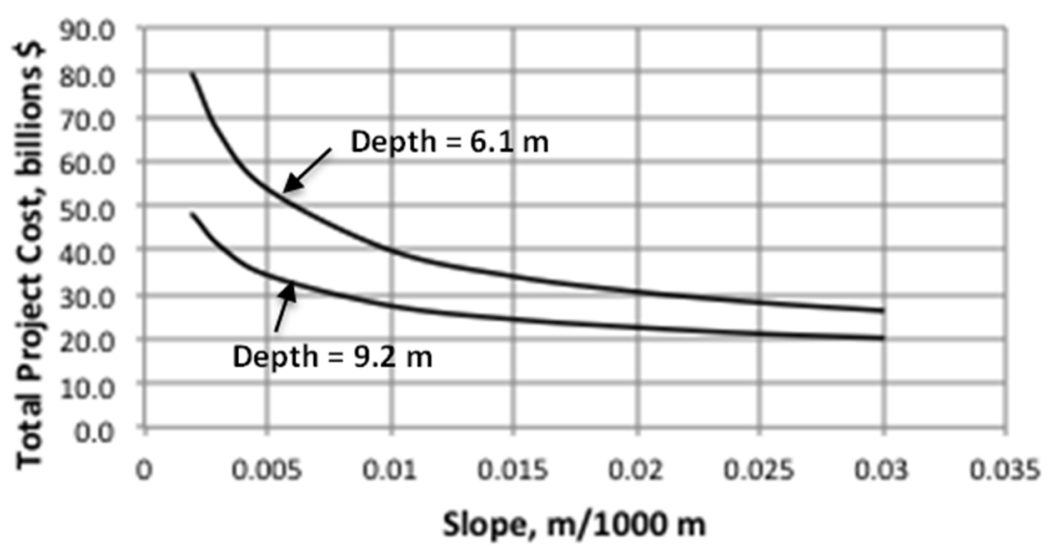

Figure 1: Total project cost vs. aqueduct slope. 
Second, Figure 2 shows the pumping power required to deliver $1000 \mathrm{~m}^{3} / \mathrm{sec}$ of water as a function of the aqueduct slope. As the slope increases, the amount of power increases due to the increase head. The pumping power is independent of water depth. This figure shows that the ideal slope is nearly zero. However, as Figure 1 shows there is a "trade-off" between slope and pumping power.

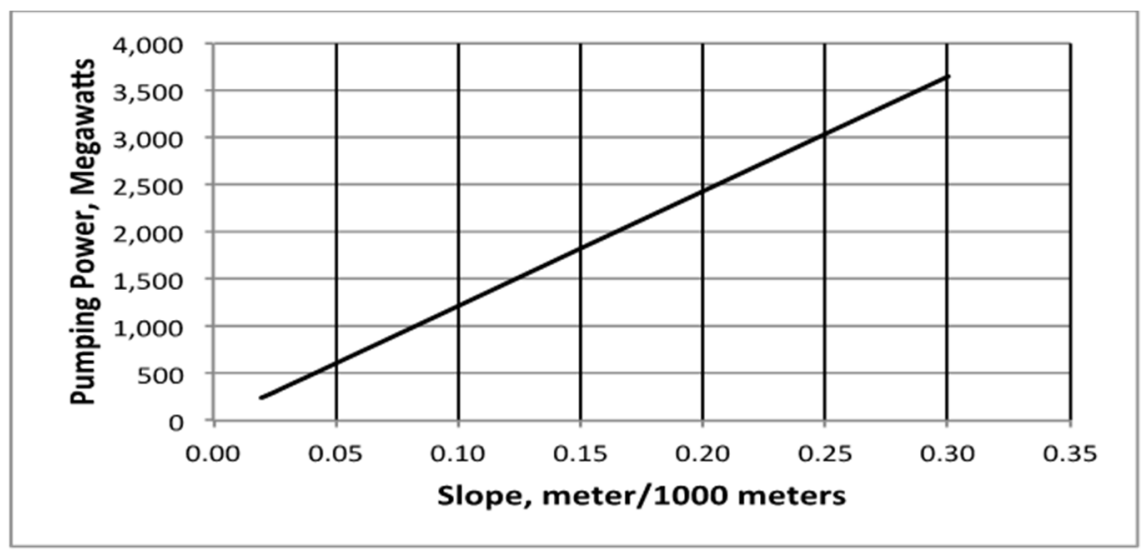

Figure 2: Pumping power vs. aqueduct slope.

Third, Figure 3 shows the total cost of energy plus capital expenditure per $1000 \mathrm{~m}^{3}$ of water required to construct and operate the aqueduct system as a function of its slope. Two curves are shown: one for a depth of $6.1 \mathrm{~m}$ and the other for a depth of $9.2 \mathrm{~m}$. It should be noted that the cost per unit volume of water delivered is the least for a depth of $9.2 \mathrm{~m}$ and the minimum occurs at a very low slope of 0.02 to $0.03 \mathrm{~m} / 100 \mathrm{~m}$ for either depth. Most importantly there is little difference in cost up to a slope of $0.015 \mathrm{~m} / 100 \mathrm{~m}$.

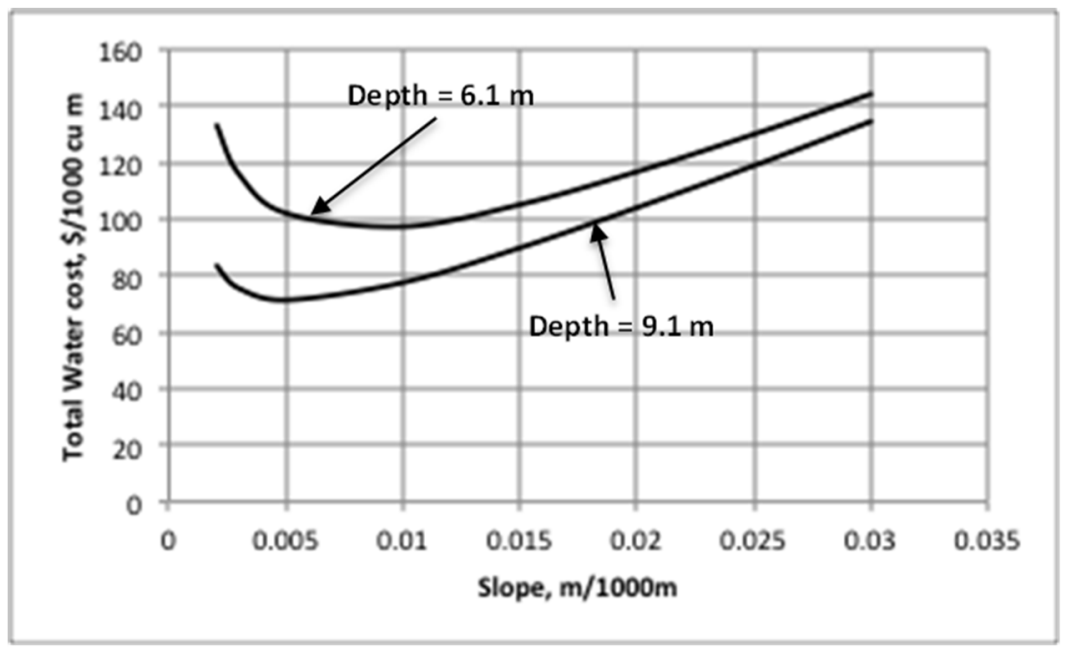

Figure 3: Total water cost vs. aqueduct slope. 
Finally, Figure 4 shows the Froude number as a function of slope. This graph shows that the Froude number is much less than unity for all situations studied. This means that in every case the flow is stable and placid.

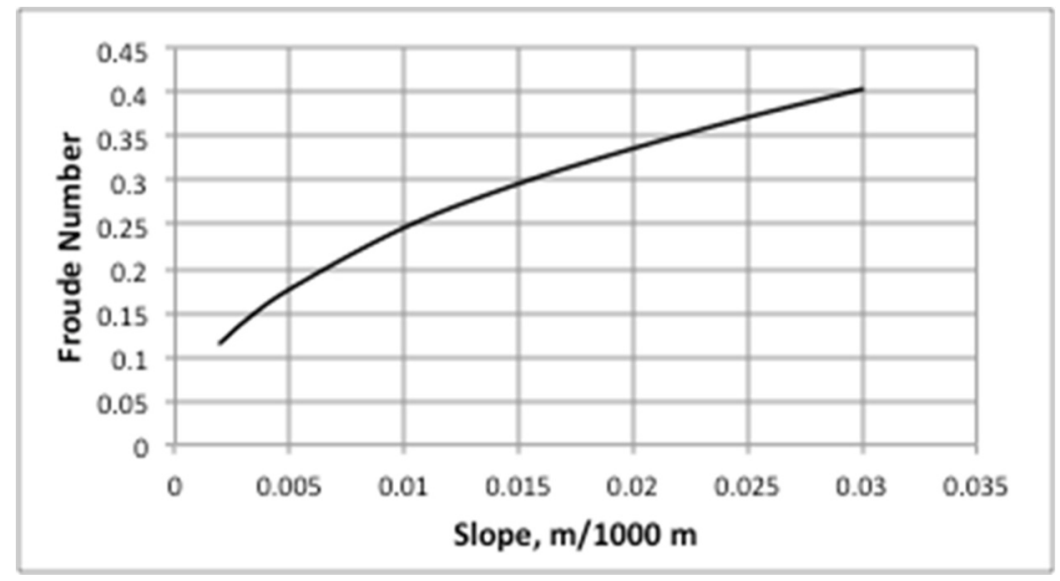

Figure 4: Froude Number vs. aqueduct slope.

The data presented in Figures 1 through 4 allow a general idea as to the best slope and depth for the aqueduct. To determine whether the RWT solution is viable, one needs to compare its cost and performance against the competitive technology (SWRO) that currently is the solution of choice. San Diego, California has just completed the most advanced, energy efficient, SWRO plant in the United States [11]. The plant produces approximately $2.2 \mathrm{~m}^{3} / \mathrm{sec}$ of fresh water. The plant consumes about 40 megawatts of power and cost one billion dollars. Table 2 shows a comparison of the performance of the RWT system proposed in this work versus SWRO based on the San Diego system. The data for the San Diego plant is scaled to the same capacity as the RWT system. Data for the aqueduct system is taken for a slope of $0.1 \mathrm{~m} / 100 \mathrm{~m}$ and a depth of $6.1 \mathrm{~m}$.

Table 2: Comparison of performance and cost of competing systems.

\begin{tabular}{|l|c|c|}
\hline Parameter & $\begin{array}{c}\text { Reverse osmosis } \\
\text { desalination }\end{array}$ & $\begin{array}{c}\text { Diverting Columbia } \\
\text { River by aqueduct }\end{array}$ \\
\hline Project cost, billion $\$$ & 454 & 39.8 \\
\hline Power consumption, MW & 17,300 & 1,232 \\
\hline Water cost, $\$ / 1000 \mathrm{~m}^{3}$ & 1,200 & 97.34 \\
\hline
\end{tabular}

\section{Conclusions}

Based on the summary data shown in Table 2, it is clear that the RWT system of diverting river water that is at the exit point of the river into the ocean is potentially 
far superior to SWRO. Specifically, the following conclusions are drawn based on the results shown above:

- The cost of building a RWT system is estimated to be less than $10 \%$ of SWRO. As a result, even if cost estimates for RWT were underestimated by a factor of 2 or 3, RWT would still be the best system.

- SWRO consumes about 15 times the electrical power of RWT. When one considers the greenhouse gas emission reduction in the use of RWT versus SWRO, RWT's overall environmental superiority is obvious.

- The cost of water produced by RWT is less than $10 \%$ of SWRO cost. In fact, the average cost of water in the United States is about $\$ 400 / \mathrm{m}^{3}$ [12] which is more than quadruple the cost of RWT water while SWRO water costs more than double the United States average cost.

Obviously, much research is needed to fully understand and control the environmental impact of RWT. Costs and detailed designs for RWT need to be fully vetted and optimization studies carried out. However, this paper clearly shows that a great opportunity to solve water shortages at very competitive costs and, at the same time, reduce greenhouse gas emissions is possible with RWT.

\section{References}

[1] World Population Prospects, United Nations, 2015.

[2] http://www.pmewswire.com/news-releases/desalination-plants-to-doubleby-2020-300166838.html (Retrieved 01/24/16).

[3] http://www.nps.gov/miss/riverfacts.htm (Retrieved 01/24/16).

[4] The Impact of Weirs on Aquatic Habitat, NSW Detailed Weir Review, NSW Department of Primary Industries, 2006.

[5] California Water Plan (Update 2013), Volumes 1-5, Published by California Department of Water Resources, 2013.

[6] Kemmerer, J.C. (May 1990). Largest Rivers in the United States. United States Geological Survey, 1990.

[7] http://www.pubs.usgs.gov/pp/0272d/report.pdf (Retrieved 7/25/16).

[8] Gauckler, P. (1867), Etudes Théoriques et Pratiques sur l'Ecoulement et le Mouvement des Eaux, Comptes Rendues de l'Académie des Sciences, Paris, France, Tome 64, pp. 818-822.

[9] Manning R. (1891). On the Flow of Water in Open Channels and Pipes. Transactions of the Institution of Civil Engineers of Ireland, 20, pp. 161207.

[10] www.artba.org/about/faq (Retrieved 7/25/16).

[11] Desalination of Seawater. American Water Works Association. ISBN 9781-58321-833-4, p. 74. 2011.

[12] The Story of Drinking Water, Fairfax County Water Authority, Fairfax, VA, 2002. 